ORIGINAL ARTICLE

\title{
Effect of sex on preactivation of the gastrocnemius and hamstring muscles
}

\section{R G DeMont, S M Lephart}

Br J Sports Med 2004;38:120-124. doi: 10.1136/bjsm.2003.000195

See end of article for authors' affiliations .....................

Correspondence to: Dr DeMont, Athletic Therapy Research Laboratory, SP165-28, Concordia University, Montreal, QC, Canada H4B 1R6; rdemont@ alcor.concordia.ca

Accepted 1 May 2003
Background: The reason for the higher incidence of anterior cruciate ligament injury from non-contact mechanisms in female athletes is not known. Stability of the joint from dynamic restraints occurs through proprioceptive and kinaesthetic mechanisms providing a flexion moment. Reflexive muscle activation is different between the sexes, but it is unclear if sex differences exist in the ability to dynamically stabilise joints through a neuromuscular feed forward process as measured by preactivation of the muscles.

Objective: To determine if the level of preactivation of the gastrocnemius and hamstring muscles during dynamic activity is affected by sex.

Methods: Thirty four healthy active subjects, evenly grouped by sex, participated in the study. Maximum voluntary contraction normalised electromyographic (EMG) activity of the quadriceps, hamstrings, and gastrocnemius muscles was recorded during downhill walking $(0.92 \mathrm{~m} / \mathrm{s})$ and running $(2.08 \mathrm{~m} / \mathrm{s})$ on a $15^{\circ}$ declined treadmill. Preactivation of the EMG signal was calculated by setting a mark 150 milliseconds before foot strike, as indicated by a footswitch. Multiple $t$ tests for sex differences of preactivity mean percentage (M-EMG\%) during the downhill activities were performed.

Results: The female subjects had a higher M-EMG\% for the medial hamstrings than the male subjects $\left(31.73\right.$ (9.89) and 23.04 (8.59) respectively; $\left.t_{(2,32)}=2.732, p=0.01\right)$ during walking. No other muscles exhibited a sex difference in M-EMG\% during either activity.

Conclusion: The female subjects in this study showed higher medial hamstring preactivation. However, this may be because they were not injured, indicating their propensity for joint stabilisation. A long term prospective study is required to eliminate this potential explanation. No sex difference in gastrocnemius preactivation was seen, adding to the controversy about whether this muscle contributes to feed forward joint stability. Further research of preactivation of the musculature of the leg is required.
A $\mathrm{n}$ anterior cruciate ligament (ACL) injury can be debilitating. Female athletes suffer more from these injuries than male athletes, ${ }^{1-3}$ and various anatomical, hormonal, and neuromuscular properties have been suggested as causative factors. ${ }^{4-6}$ Muscle contraction can decrease the incidence of injury to the knee, because strength and coordination between the flexors of the knee are thought to protect it from shear forces that stress the ACL. This muscle tension may be enough to prevent injury. Although it is known that muscular control is altered with injury, ${ }^{7}$ whether there is a sex difference in muscle preactivity before injury is not known. The preactivation of muscles during dynamic activity can be measured by electromyography (EMG), and understanding the normal preactivation of the gastrocnemius and hamstring musculature will provide a framework that can be used to devise prevention programmes and manage rehabilitation of the ACL injured athlete. If preactivation contributes to joint stability, greater preactivation would be expected in people less susceptible to ligament injury. The purpose of this study was to determine the effects of sex on preactivation of the gastrocnemius and hamstring muscles.

The neuromuscular components of dynamic joint stability in healthy and ACL deficient subjects are common areas of research. Preparatory and reflexive muscle activation are two neuromuscular processes that determine muscle activity and contribute to functional joint stability. The muscle spindle contributes to muscle tension through a feedback reflexive stretch mechanism, but the process most likely to benefit the joint dynamically is through information from by the $\gamma$ feedback loop associated with the muscle spindle. ${ }^{8}$ This feed forward system may be the best approach to preventive strategies. Theoretically, protection can be accomplished through generation of muscular tension as the result of efferent information from the descending drive and afferent information from cutaneous and articular mechanoreceptors. ${ }^{9}$ The information provided from the muscle spindle is modulated by the tension within the muscle spindle, which affects the $\alpha$ motoneurone. This modulation updates the muscle tension and may protect the joint through dynamic stability and "self" regulation.

Tension is crucial to this feed forward paradigm of the muscle spindle modifying the neural signal back to the muscle. ${ }^{10}$ The tension of the muscle spindle may be determined by both intrinsic and extrinsic modes. The intrinsic mode is a function of the viscoelastic soft tissue properties measured by the resistance to length changes. ${ }^{11}$ The extrinsic factor is the previously mentioned adjustment resulting from the afferent input. ${ }^{9}$ Each of these factors may influence the sensitivity and therefore the protective ability of the system. The tension produced by preactivation of a muscle before a stressing experience may improve regulation of the muscle activity, thereby increasing its ability to protect the joint. In addition, a learned task will prepare the joint for increased stress by a preparatory muscle contraction based on an experienced expectation, through an increase in the sensitivity of the muscle spindle. ${ }^{1012}$

The control of the knee position during dynamic movement by the nervous and muscular systems may depend on

Abbreviations: $A C L$, anterior cruciate ligament; $E M G$,

electromyography; $M G$, medial gastrocnemius; $M H$, medial hamstring; MVC, maximum voluntary contraction; LG, lateral gastrocnemius; $L H$, lateral hamstring 
activation of the muscles surrounding the joint before (preactivity) the occurrence of stressful events. ${ }^{7}$ The quadriceps, as well as being able to extend the knee, can also create an anterior tibial translation force, which can put stress on the ACL. ${ }^{13}{ }^{14}$ The ability of this force alone to jeopardise the ACL has been questioned, ${ }^{15}$ but, in combination with other movements, it may contribute to injury. In contrast, the hamstrings have a distal insertion into the tibia crossing the posterior side of the knee and are thought to have the reverse effect to the quadriceps. As the hamstrings contract, a posterior force is imposed on the tibiofemoral joint, which reduces stress on the ACL. ${ }^{13}{ }^{16}{ }^{17}$ Less information is available on the role of the gastrocnemius muscle in knee joint stability. Most studies that have included it in their analysis $^{161819}$ do not report fully on its role.

Lass et $a l^{20}$ found an increase in hamstring and gastrocnemius EMG onset time in ACL deficient patients walking up an incline of $20^{\circ}$ and $25^{\circ}$. Although they support the theory of the hamstring reducing stress in the ACL, they also suggest a decrease in ACL stress through the activity of the gastrocnemius. The gastrocnemius theory is supported by the increase in onset of EMG during walking at inclines of $0^{\circ}, 5^{\circ}$, $10^{\circ}$, and $15^{\circ}$. Hamstring activity did not increase at these inclines, yet the duration of the quadriceps and gastrocnemius activity was correspondingly higher in the ACL deficient patients. However, this may be due to the increased dorsiflexion of incline walking. In contrast, Fleming et $a^{21}$ found increased strain in a study of ACL tension during gastrocnemius contraction.

The strain placed on the ACL depends on the knee joint angle, the compressive forces on the joint, and the function of the muscles crossing the joint. ${ }^{13-1622-26}$ In a study of human subjects walking downhill, Kuster et al ${ }^{24}$ found a maximum tibiofemoral shear force at $20 \%$ of the gait cycle. The force on average was greater for female subjects ( 1.7 times body weight) than for male subjects ( 1.2 times body weight). In a separate study, Kuster ${ }^{26}$ found that $20 \%$ of the compressive forces were due to the flexors of the knee.

The demonstration of muscle preactivation (preactivity) is less prevalent in the literature than reactive or post-loading responses, but it may influence these responses. Preactivity was measured in the arm muscles of subjects participating in a drop landing at an unexpected distance. ${ }^{27}$ When an increase in triceps EMG preactivity was found, it was accompanied by an increased EMG response after contact. Although this response was measured in the arms, it was attributed to an affected stretch reflex, which would also probably occur in the legs. Central pattern generation was ruled out by blinding of the task. Increased preactivity was also shown in power athletes, ${ }^{28}$ and with braking (slowing down) from a supramaximal run. ${ }^{29}$ These training and higher dynamic activities may require greater preactivity to aid injury prevention. In a study of external joint load effects on muscle activation, preactivation was shown to increase readiness to accept a force..$^{11}$ In relation to injury, differences in bilateral quadriceps and lateral gastrocnemius preactivity were shown in ACL deficient subjects when walking downhill. ${ }^{7}$ As increased stiffness of the joint improves stability, ${ }^{22} 23$ the implication of these results for injury prevention is that greater tension will increase the responsiveness of the muscles, providing increased dynamic stability.

There has been no research on the normal preactivation of the hamstrings and gastrocnemius, or sex differences in preactivation, during dynamic activities in healthy subjects.

\section{METHODS} Subjects

The subjects comprised 17 women (mean (SD) height 164.5 (6.4) cm, weight 62.2 (10.1) kg, age 20.1 (1.4) years) and 17 men (mean (SD) height $179.4 \quad(4.3) \mathrm{cm}$, weight 80.8 (12.0) kg, and age 22.5 (3.1) years). They were all recreationally active (participated in aerobic and strength training three times a week) and had no history of knee pathology. Each subject gave written informed consent.

Before electrode placement, an area of about $5 \mathrm{~cm}^{2}$ around the anatomical site was shaved of body hair (when required) and abraded with an emery board. The skin was cleaned with isopropyl alcohol to remove sebaceous oils and abraded skin cells. Surface electrodes (Ag-Ag/Cl, Blue Sensors; Medicotest Marketing Inc, Rolling Meadows, Illinois, USA) were placed at the prepared location so that the centres of the electrode were within $2 \mathrm{~cm}$ of each other. The accepted impedance was $2 \mathrm{k} \Omega$.

EMG activity was measured from the vastus medialis oblique, medial hamstring ( $\mathrm{MH})$, and lateral hamstring ( $\mathrm{LH})$ in the thigh, and the medial gastrocnemius (MG), lateral gastrocnemius (LG), and soleus of the dominant leg. Electrode placement for the vastus medialis oblique bisected the muscle anteroposteriorly, and was at a point distal from the motor point of the muscle half way to the insertion of the quadriceps tendon. The MH electrodes were placed over the muscle belly half way between the ischial tuberosity and the tibial insertion point, at least $5 \mathrm{~cm}$ proximal to the musculotendinous junction. The LH electrodes were placed over the biceps femoris muscle halfway between the ischial tuberosity and the fibular insertion site, and a minimum of $5 \mathrm{~cm}$ proximal to the musculotendinous junction. The MG electrode location was centrally in a mediolateral fashion and distal from the midpoint of the belly to the tendinous junction. The LG electrodes were placed in a similar fashion, and placement of the MG was slightly higher because of the more proximal orientation to the muscle. The soleus electrodes were placed distal to the lateral head of the gastrocnemius on the posterior surface of the leg to avoid cross talk from the peroneal muscles. Cross talk was ruled out through isometric contraction of the muscles (eversion versus plantar flexion) A reference electrode for the EMG system was placed over the tibia. Two footswitches were placed on the plantar surface of the foot to indicate heel contact and toe off point of the gait cycle.

\section{EMG equipment and processing}

The Noraxon Telemyo EMG System (Noraxon, Scotsdale, Arizona, USA) is a telemetry system that is integrated with a computer equipped with collection and analysis software (MyoResearch97, Noraxon). The footswitch signals were collected through this telemetry system, and integrated into the analysis software acquisition. Calibration of the telemetry system consisted of setting the values of the EMG to zero when the muscles were at rest. The foot switches were set to zero when the foot was not in contact with the ground. Calibration was performed with the subject lying supine on the table.

The EMG signals from the six muscles and the footswitch were collected through this system and sampled at $1000 \mathrm{~Hz}$ with a common mode rejection ratio of $130 \mathrm{db}$. The signals were then bandpass filtered (Butterworth) below $10 \mathrm{~Hz}$ and above $500 \mathrm{~Hz}$, amplified (gain 500), and transferred using an eight channel FM transmitter to a receiver, where they were further amplified (gain 500, total gain 1000). The signals were then digitised by an analogue to digital converter (DAS1000; Keithley Instruments Inc, Taunton, Massachusetts, USA), and further processed by full wave rectification and normalisation (\%) to the maximum voluntary contraction (MVC). Markers were placed at each heel strike and toe off so that normalisation periods coincided with the gait cycle. For preactivity comparison between the muscles, a 
150 millisecond interval before foot contact was processed from 10 trials for mean activity.

\section{Isokinetic dynamometer}

The Biodex System II Isokinetic Dynamometer (Biodex Medical Systems Inc, Shirley, New York, USA) provided resistance for the MVC in a closed kinetic chain position. Subject positioning was an inclined sitting position, with backrest set a $45^{\circ}$. The position of the leg was knee extended at $60^{\circ}$ and the foot at $30^{\circ}$ from neutral $\left(30^{\circ}\right.$ of plantarflexion). It is possible that this position did not develop maximal values compared with an isolated open chain contraction, but the goal was to use a closed chain with similar positioning to the test situation. This position also relates more closely to the foot strike position than open chain activities.

\section{Dynamic activities}

After the MVC on the dynamometer, the subject completed the dynamic activities of walking and running downhill in a counter balanced order. These activities were performed on the Biodex treadmill, which had variable speeds and incline/ decline adjustments. Calibration of the EMG and footswitches took place before initiation of the walking and running activities, with the subject lying supine with muscles relaxed. Walking downhill was performed on a $15^{\circ}$ decline at $0.92 \mathrm{~m} / \mathrm{s}$ (3.3 kph, $2 \mathrm{mph}$ ), and running downhill used the same decline and at a speed of $2.08 \mathrm{~m} / \mathrm{s}(4.8 \mathrm{kph}, 3 \mathrm{mph})$. The six muscles were analysed for the level of normalised EMG activity during the 150 milliseconds before heel contact for both walking and running downhill.

\section{Statistical analysis}

The dependent variables were the EMG mean activity of each muscle. The independent variables were the walking and running dynamic conditions. The $\alpha$ level was set a priori at $\mathrm{p}=0.05$, and multiple $t$ tests were used to detect sex differences in the preactivity of each muscle during the downhill walking.

\section{RESULTS}

Table 1 lists the mean (SD) for each muscle. For the $\mathrm{MH}$, a significant sex difference was observed during walking downhill. For this muscle, the female subjects had a higher level of activity than their male counterparts (31.73 (9.890 and $23.04(8.59)$ respectively; $\left.t_{(2,32)}=2.732, p=0.01\right)$. The other five muscles did not show any significant sex differences. No differences were observed in preactivation EMG during the running activity for any muscle.

\section{DISCUSSION}

Maintenance of joint congruency is important in prevention of injury. Both the ligamentous structures and the muscular system contribute. ${ }^{23}{ }^{30}$ The role of the muscular system is particularly important when the static restraints are jeopardised and therefore not providing restraint to abnormal motion within the joint. In the downhill walking and running activities of this study, muscle activation before the foot made contact with the ground was measured. Six muscles in the healthy subjects were analysed for the level of normalised EMG mean activity 150 milliseconds before heel contact during walking and running downhill. We predicted that the male subjects would exhibit higher normalised muscle activity for these tasks, indicating a propensity for joint stabilisation during foot contact. Injury incidence in male athletes is lower than in female athletes, ${ }^{12}$ and a possible explanation is a sex difference in hamstring muscle activity, ${ }^{151731}$ as hamstrings control anterior displacement. ${ }^{22}{ }^{23}$ As men have less injury and muscle preactivation increases joint stability, it should follow that they should show higher levels of muscle preactivation. This was not found in this study. It should be noted that the subjects in this study were healthy, so the women had not shown any tendency to injury to date. It would be of interest to assess their injury rate over the next 5-10 years to see if they remained injury free. A prospective study would also be of value to determine if the preactivation level affects the injury rate.

Table 1 Preactivation group means, standard deviation, standard error of the mean, $p$ value, and $95 \%$ confidence interval for each muscle and activity

\begin{tabular}{|c|c|c|c|c|c|c|c|}
\hline \multirow[b]{2}{*}{ Activity } & \multirow[b]{2}{*}{ Sex } & \multirow[b]{2}{*}{ Mean } & \multirow[b]{2}{*}{ SD } & \multirow[b]{2}{*}{ SEM } & \multirow[b]{2}{*}{$p$ Value } & \multicolumn{2}{|l|}{$95 \% \mathrm{Cl}$} \\
\hline & & & & & & Lower & Upper \\
\hline JLG & $\begin{array}{l}\text { Female } \\
\text { Male }\end{array}$ & $\begin{array}{l}21.66 \\
20.69\end{array}$ & $\begin{array}{l}16.88 \\
20.01\end{array}$ & $\begin{array}{l}4.09 \\
4.85\end{array}$ & 0.88 & -11.9625 & 13.9002 \\
\hline JLH & $\begin{array}{l}\text { Female } \\
\text { Male }\end{array}$ & $\begin{array}{l}37.84 \\
36.96\end{array}$ & $\begin{array}{l}11.59 \\
18.16\end{array}$ & $\begin{array}{l}2.81 \\
4.40\end{array}$ & 0.867 & -9.7611 & 11.5258 \\
\hline JMG & $\begin{array}{l}\text { Female } \\
\text { Male }\end{array}$ & $\begin{array}{l}41.02 \\
38.19\end{array}$ & $\begin{array}{l}22.18 \\
22.30\end{array}$ & $\begin{array}{l}5.38 \\
5.41\end{array}$ & 0.713 & -12.7103 & 18.3632 \\
\hline JMH & $\begin{array}{l}\text { Female } \\
\text { Male }\end{array}$ & $\begin{array}{l}43.10 \\
39.71\end{array}$ & $\begin{array}{l}10.22 \\
13.84\end{array}$ & $\begin{array}{l}2.48 \\
3.36\end{array}$ & 0.422 & -5.1026 & 11.8967 \\
\hline JVMO & $\begin{array}{l}\text { Female } \\
\text { Male }\end{array}$ & $\begin{array}{l}27.03 \\
31.74\end{array}$ & $\begin{array}{l}13.14 \\
13.40\end{array}$ & $\begin{array}{l}3.19 \\
3.25\end{array}$ & 0.309 & -13.9812 & 4.5612 \\
\hline JSOL & $\begin{array}{l}\text { Female } \\
\text { Male }\end{array}$ & $\begin{array}{l}23.43 \\
24.40\end{array}$ & $\begin{array}{l}11.61 \\
14.32\end{array}$ & $\begin{array}{l}2.81 \\
3.47\end{array}$ & 0.83 & -10.0767 & 8.1367 \\
\hline WLG & $\begin{array}{l}\text { Female } \\
\text { Male }\end{array}$ & $\begin{array}{l}7.52 \\
7.09\end{array}$ & $\begin{array}{l}5.05 \\
6.02\end{array}$ & $\begin{array}{l}1.23 \\
1.46\end{array}$ & 0.82 & -3.4443 & 4.3207 \\
\hline WLH & $\begin{array}{l}\text { Female } \\
\text { Male }\end{array}$ & $\begin{array}{l}28.54 \\
25.06\end{array}$ & $\begin{array}{l}10.10 \\
11.13\end{array}$ & $\begin{array}{l}2.45 \\
2.70\end{array}$ & 0.347 & -3.9429 & 10.91 \\
\hline WMG & $\begin{array}{l}\text { Female } \\
\text { Male }\end{array}$ & $\begin{array}{l}18.27 \\
15.82\end{array}$ & $\begin{array}{l}21.85 \\
17.87\end{array}$ & $\begin{array}{l}5.30 \\
4.33\end{array}$ & 0.722 & -11.487 & 16.4 \\
\hline WMH & $\begin{array}{l}\text { Female } \\
\text { Male }\end{array}$ & $\begin{array}{l}31.73 \\
23.04\end{array}$ & $\begin{array}{l}9.90 \\
8.60\end{array}$ & $\begin{array}{l}2.40 \\
2.09\end{array}$ & $0.01^{*}$ & 2.2108 & 15.1645 \\
\hline WVMO & $\begin{array}{l}\text { Female } \\
\text { Male }\end{array}$ & $\begin{array}{l}26.68 \\
26.66\end{array}$ & $\begin{array}{l}12.24 \\
12.62\end{array}$ & $\begin{array}{l}2.97 \\
3.06\end{array}$ & 0.995 & -8.6549 & 8.7102 \\
\hline WSOL & $\begin{array}{l}\text { Female } \\
\text { Male }\end{array}$ & $\begin{array}{l}17.54 \\
13.46\end{array}$ & $\begin{array}{l}10.62 \\
10.21\end{array}$ & $\begin{array}{l}2.50 \\
2.47\end{array}$ & 0.262 & -3.1957 & 11.3639 \\
\hline
\end{tabular}


The ability of the hamstrings to control tibial position may not necessarily be related to the strength of the contraction as determined by electrical muscle activity. More electrical activity when normalised to the MVC indicates an increase in the neural component for the selected task, and an implied increase in force output. Although we did not measure knee joint laxity, female athletes typically have greater joint laxity, ${ }^{6}{ }^{32}$ and it is possible that the increased activity is a preparatory effort to protect the knee from increased anterior shear force. Given that each subject had motor programming associated with walking downhill available, the preactivation could be related to drop height and expected ground contact interval, which in this study is the distance from the height of the swing phase to the treadmill at the designated inclination. The relation between expected contact time and preactivation level has been established..$^{33}$ Santello and McDonagh $^{33}$ found that the level of preactivity was based on the height of the descent, which affected the expected foot contact time. Similarly, in the arms, Lacquaniti and Maioli ${ }^{35}$ found that preactivation levels related to height, when they measured catching of a ball dropped from different heights.

The relation of preactivation to height and speed may explain the sex difference in preactivation of the MH. The treadmill speed was the same for the women and men. At a set velocity, elite male athletes are more efficient at running than elite female athletes, ${ }^{36}$ but we did not find any differences at the faster speed. Given a general height difference, women walk with a shorter stride, which may marginally increase the complexity (through speedier walking) of the task, resulting in higher EMG activity levels. The running speed was slow enough that no subjects had difficulty with this activity. This may explain why differences in activity levels associated with the stride length mechanism did not translate into a sex difference for the run.

The incidence of non-contact injuries was the basis for predicting a higher level of stabilising muscle activity in the men. A preactivation difference did exist for the MH between the sexes, with the women having higher EMG activity means. A healthy group was used in this study, so it is incorrect to apply these findings to injury susceptible subjects. It is not known if the women in this study are susceptible to ACL injury. If they were susceptible to injury through a lack of stabilising hamstring activation before foot contact with the ground, lower activity in these muscles would be expected in the women-that is, the protection necessary to prevent injury would not be provided. Although non-contact ACL injuries result from some deviation from normal and trained movement patterns during cutting and deceleration, ${ }^{37}$ the stable joint has a degree of stiffness through muscle contraction before receiving the force. Previous research found an increase in LH EMG amplitude and area after landing from a jump, ${ }^{38}$ and delayed contraction of $\mathrm{MH}$ in landing when fatigued. ${ }^{6}$ Although we found increased preactivation of $\mathrm{MH}$ in our female subjects, we did not expose the athletes to a fatiguing series of exercises before testing, which may contribute to the muscle emphasis change between $\mathrm{MH}$ and $\mathrm{LH}$. Another explanation of our finding of increased $\mathrm{MH}$ preactivity in female athletes is that the increased $\mathrm{MH}$ preactivity may provide increased stability to counteract the valgus position recently linked to female landing accompanied by ACL injury. ${ }^{39} 40$ Unfortunately, we did not make the appropriate measurements, but our finding does support further investigation of this association.

As only a difference in $\mathrm{MH}$ activation was found, activity of the hamstrings, quadriceps, and gastrocnemius could be investigated on the basis of preactivation timing differences or the rate of increase in activity between these muscle groups. In this healthy cohort, the women exhibited more

\section{Take home message}

Preactivation may be the key to reducing non-contact ligament injury to the knee. There is a sex difference in the stabilising effect of the hamstring, as measured by preactivation, but further research is needed to understand the parameters of preactivation and its ability to prevent injury.

$\mathrm{MH}$ activity than the men, indicating a learned pattern of joint protection.

The gastrocnemius is also linked to ACL injury and joint stability. The LG has been associated with movements at the knee, and the MG with ankle movements. ${ }^{41}$ Some research$\operatorname{ers}^{18}{ }^{19}$ believe that, as it is a knee flexor muscle, the gastrocnemius provides stability to the joint by resisting anterior tibial displacement. This phenomenon was exhibited through posterior perturbation of the knee at the level of the superior tibia. LG preactivation differences have been shown bilaterally in ACL deficient female subjects, ${ }^{7}$ supporting an association with the knee where the LG exhibited decreased preactivation after injury. The gastrocnemius was previously modelled to oppose the ACL, ${ }^{16}$ and this was supported through electrical muscle stimulation while measuring ACL tension. ${ }^{21}$ These studies provide conflicting results, suggesting that the role of the gastrocnemius requires further investigation. In our study, the gastrocnemius did not show a sex difference in EMG preactivation for either downhill walking or running. Whether the gastrocnemius is a stabiliser or contributes to tibial anterior displacement, a sex difference for these roles was not exhibited through the preactivation levels found in this study. There was no sex difference in MG or LG activation patterns for these activities, indicating that they do not have the same stabilising pre-emptive role in downhill walking and running as the hamstrings. This normal preactivation of the gastrocnemius-that is, not higher in women-increases questions on its stabilising effects, and is in disagreement with the results of reactive activation studies. ${ }^{19}$

This study was a preliminary step to examining sex differences in muscle preactivation. The decline treadmill tasks were used to increase the complexity of movement in an effort to be more representative of at risk movements. Although these tasks were more difficult than level walking or running, they are not as difficult as multidirectional or acceleration/deceleration tasks. Multiple directions and faster speeds are involved in most sports, requiring a more elaborate muscle activation pattern. With this limitation, the increase in $\mathrm{MH}$ preactivation with walking suggests that preactivation is worth further investigation.

\section{Authors' affiliations \\ R G DeMont, S M Lephart, Neuromuscular Research Laboratory, University of Pittsburgh, Pittsburgh, PA, USA}

\section{REFERENCES}

1 Arendt E, Dick R. Knee injury patterns among men and women in collegiate basketball and soccer. Am J Sports Med 1995;23:694-701.

2 Arendt E, Dick R. Anterior cruciate ligament injury patterns among collegiate men and women. J Athl Train 1998;34:86-92.

3 Malone T, Hardaker W, Garrett W. Relationship of gender to anterior cruciate ligament injuries in intercollegiate basketball players. J South Orthop Assoc 1993;36-39:36-9.

4 Barrett G. Relationship of anterior cruciate ligament injury to notch width index: a retrospective study. J Miss State Med Assoc 1992;33:279-83.

5 Lephart S. Proprioception following anterior cruciate ligament reconstruction. Journal of Sport Rehabilitation 1992:188-96.

6 Rozzi S, Lephart S, Gear W, et al. Knee joint laxity and neuromuscular characteristics of male and female soccer and basketball players. Am J Sports Med 1999;27:312-19. 
7 DeMont R. Muscle pre-activity among ACL-R, ACL-D, and control female subjects during lower extremity functional activities. J Athl Train 1999;34:115-20.

8 Bergenheim $M$, Johansson $\mathrm{H}$, Pedersen J. The role of the gamma-system for improving information transmission in populations of la afferents. Neurosci Res 1995;23:207-15

9 Johansson H, Siolander P, Sojka P. Fusimotor reflex profiles of individual triceps surae primary muscle spindle afferents assessed with multi-afferent recording technique. J Physiol (Paris) 1991;85:6-19.

10 Johansson H, Sojka P. Pathophysiological mechanisms involved in genesis and spread of muscular tension in occupational muscle pain and in chronic musculoskeletal pain syndromes: a hypothesis. Med Hypotheses 1991;35:196-203.

11 Grillner S. A role for muscle stiffness in meeting the changing postural and locomotor requirements for the force development by the ankle extensors. Acta Physiol Scand 1972;86:92-108.

12 Johansson H, Sjolander P, Sojka P. A sensory role for the cruciate ligaments. Clin Orthop 1991:161-78.

13 Shelburne KB, Pandy MG. A musculoskeletal model of the knee for evaluating ligament forces during isometric contractions. J Biomech 1997;30:163-76.

14 Lutz GE, Palmitier RA, An KN, et al. Comparison of tibiofemoral joint forces during open-kinetic-chain and closed-kinetic-chain exercises. J Bone Joint Surg [Am] 1993;75:732-9.

15 Aune A, Ekeland A, Nordsletten L. Effect of quadriceps or hamstring contraction on the anterior shear force to anterior cruciate ligament failure. An in vivo study in the rat. Acta Orthop Scand 1995;66:261-5.

16 Collins J, O'Connor J. Muscle-ligament interactions at the knee during walking. Proceedings of the Institution of Mechanical Engineers. Part $\mathrm{H}$, Journal of Engineering in Medicine 1991;205:11-18.

17 Baratta R, Solomonow M, Zhou BH, et al. Muscular coactivation. The role of the antagonist musculature in maintaining knee stability. Am J Sports Med 1988;16:113-22.

18 Woitys E, Huston L. Neuromuscular performance in normal and anterior cruciate ligament-deficient lower extremities. Am J Sports Med 1994;22:89-104.

19 Huston L, Woitys E. Neuromuscular performance characteristics elite female athletes. Am J Sports Med 1996;24:427-36.

20 Lass $\mathbf{P}$, Kaalund S, leFevre S, et al. Muscle coordination following rupture of the anterior cruciate ligament. Electromyographic studies of 14 patients. Acta Orthop Scand 1991;62:9-14.

21 Fleming BC, Renstrom PA, Ohlen G, et al. The gastrocnemius muscle is an antagonist of the anterior cruciate ligament. J Orthop Res 2001;19:1178-84.

22 Renstrom P. Strain within the anterior cruciate ligament during hamstring and quadriceps activity. Am J Sports Med 1986;14:83-7.

23 Goldfuss AJ, Morehouse CA, LeVeau BF. Effect of muscular tension on knee stability. Med Sci Sports Exerc 1973;5:267-71.
24 Kuster M, Wood GA, Sakurai S, et al. Downhill walking: a stressful task for the anterior cruciate ligament? A biomechanical study with clinical implications. Knee Surg Sports Traumatol Arthrosc 1994;2:2-7.

25 Escamilla RF, Fleisig GS, Zheng N, et al. Biomechanics of the knee during closed kinetic chain and open kinetic chain exercises. Med Sci Sports Exerc 1998;30:556-69.

26 Kuster $M$. Joint load considerations in total knee repalcement. J Bone Joint Surg [Br] 1997;79:109-13.

27 Dietz V, Noth J, Schmidtbleicher D. Interaction between pre-activity and stretch reflex in human triceps brachii during landing from forward falls. J Physiol 1981;311:113-25.

28 Kyrolainen H, Komi PV. Differences in mechanical efficiency between powerand endurance-trained athletes while jumping [erratum published in Eur J Appl Physiol 1995;70:373]. Eur J Appl Physiol Occup Physiol 1995; 70:36-44.

29 Mero A, Komi PV. Electromyographic activity in sprinting at speeds ranging from sub-maximal to supra-maximal. Med Sci Sports Exerc 1987:19:266-74.

30 Markoff K. Combined knee loading states that generate high anterior cruciate ligament forces. J Orthop Res 1995;13:930-5.

31 Beard DJ, Kyberd PJ, O'Connor JJ, et al. Reflex hamstring contraction latency in anterior cruciate ligament deficiency. J Orthop Res 1994;12:219-28.

32 Barrack R. Joint Laxity and proprioception in the knee. Phys Sportsmed 1983;11:130-5.

33 Santello $M$, McDonagh MJ. The control of timing and amplitude of EMG activity in landing movements in humans. Exp Physiol 1998;83:857-74.

34 Lacquaniti F, Maioli $C$. The role of preparation in tuning anticipatory and reflex responses during catching. J Neurosci 1989;9:134-48

35 Lacquaniti F, Maioli C. Anticipatory and reflex coactivation of antagonist muscles in catching. Brain Res 1987:406:373-8.

36 Daniels J, Daniels N. Running economy of elite male and elite female runners. Med Sci Sports Exerc 1992;24:483-9.

37 Nyland JA, Caborn DN, Shapiro R, et al. Crossover cutting during hamstring fatigue produces transevers plane control deficits. J Athl Train 1999;34:137-43.

38 Rozzi SL, Lephart SM, Fu FH. Effects of muscular fatigue on knee joint laxity and neuromuscular characteristics of male and female athletes. J Ath/ Train 1999;34:106-14.

39 Hewett TE, Lindenfeld TN, Riccobene JV, et al. The effect of neuromuscular training on the incidence of knee injury in female athletes. A prospective study [comment]. Am J Sports Med 1999;27:699-706.

40 Hewett TE. Neuromuscular and hormonal factors associated with knee injuries in female athletes. Strategies for intervention. Sports Med 2000;29:313-27.

41 Wolf SL, Ammerman J, Jann B. Organization of responses in human lateral gastrocnemius muscle to specified body perturbations. J Electromyogr Kinesio 1998;8:11-21. 